\title{
1 Comparison and validation of physical wave parameterizations in 2 spectral wave models
}

3 Justin E. Stopa ${ }^{1}$, Fabrice Ardhuin ${ }^{12}$, Alexander Bababin ${ }^{3}$, Stefan Zieger ${ }^{3}$

\section{Abstract}

5 Recent developments in the physical parameterizations available in spectral wave models have 6 already been validated, but there is little information on their relative performance especially 7 with focus on the higher order spectral moments and wave partitions. This study concentrates on 8 documenting their strengths and limitations using satellite measurements, buoy spectra, and a 9 comparison between the different models. It is confirmed that all models perform well in terms 10 of significant wave heights; however higher-order moments have larger errors. The partition wave quantities perform well in terms of direction and frequency but the magnitude and directional spread typically have larger discrepancies. The high-frequency tail is examined through the mean square slope using satellites and buoys. From this analysis it is clear that some models behave better than the others, suggesting their parameterizations match the physical processes reasonably well. However none of the models are entirely satisfactory, pointing to poorly constrained parameterizations or missing physical processes. The major space-time differences between the models are related to the swell field stressing the importance of describing its evolution. An example swell field confirms the wave heights can be notably different between model configurations while the directional distributions remain similar. It is clear that all models have difficulty in describing the directional spread. Therefore, knowledge of the source term directional distributions is paramount in improving the wave model physics in 22 the future.

23 Keywords: WAVEWATCH III, spectral wave modeling, wind wave modeling, wave hindcasting, source terms, higher order wave moments, swell dissipation

\section{Introduction}

\footnotetext{
${ }^{1}$ Ifremer, Laboratorie d'Oceanographie Sptaiale (LOS), Corresponding Author, email: justin.stopa@ifremer.fr

${ }^{2}$ Ifremer, Laboratorie de Physique des Oceans (LPO), email: fabrice.ardhuin@ifremer.fr

${ }^{3}$ Swinburne University of Technology, Centre of Ocean Engineering, Science and Technology, email: ababanin@swin.edu.au, szieger@swin.edu.au
} 
Forecasting and hindcasting marine conditions in sufficient detail have become increasingly important to society. Modeled wave datasets have greatly enhanced our knowledge of the ocean environment by supplementing in-situ and remotely sensed data. Numerical wave models have been in operation for over 50 years (Gelci et al. 1957) providing an essential part of marine weather forecasts and climatology that are used for shipping, offshore operations, the management of coastal hazards, research purposes, and recreational activities. In response to the growing need for accurate sea-state information, the wave modeling community has made significant developments in the physical parameterizations and improved the model performance (WAMDI 1988, Komen et al. 1994, Tolman and Chalikov 1996, Ardhuin et al., 2010; Bidlot et al., 2007; Rogers et al. 2012).

WAVEWATCH-III (hereinafter WW3) is based on the spectral wave model that was initially developed by Tolman et al., (2002). This code has been expanded into an open source community modeling framework, with the addition of many new features and options now available in version 4.18 that was recently made public (Tolman et al. 2014). The integration of advances from several groups outside NOAA has been made possible by the National Oceanographic Partnership Program, as described by Tolman et al., (2013). As the number of users and applications increases, so does the need for shared knowledge of the performance by the various options in the WW3 framework. The accuracy of the source term packages listed in Table 1 and referred to as ST2, ST3, ST4, and ST6 will be assessed. Each model describes the wind generation and whitecapping dissipation differently. In deep water these are the dominant processes with the non-linear four-wave interaction. The wave-wave interaction is the same for all models and is parameterized by Hasselmann et al., (1985b) with only a reduction in the strength of this interaction in ST2 (Tolman and Chalikov 1996). For a specific discussion of shallow water processes and their improvements in WW3 see Roland and Ardhuin (2014).

The models generally produce results that compare well with measurements of the significant wave heights (e.g. Caires et al., 2004; Dee et al., 2011; Chawla et al., 2013; Stopa and Cheung, 2014a). The details and validity of the higher order spectral moments have large differences especially in ST3 and ST4 as demonstrated by Rascle and Ardhuin (2013). Therefore it is expected that the higher order moments from others will have less validity. The accurate description of the high frequency wave components dictates the momentum flux between the ocean and atmosphere, having implications in coupled climate systems (e.g. Cavaleri et al. 
57 2012). Furthermore high frequency waves have important applications in remote sensing because 58 the measured signal responds to sea-state through the mean squared slope.

In view of these consequences the validity of the higher order wave moments must be established and interrelated for the different parameterizations. Here we extend our efforts to document the validity of additional moments of the wave spectrum like the orbital wave velocity, average wave period, mean square slope, and Stokes drift that might be useful for some communities. Our purpose is to provide an overall assessment of the most up-to-date source terms under real conditions. In order to simplify the discussion, we focus our efforts at the global scale, with a hindcast of 2011. In-situ wave spectra from the National Data Buoy Center (NDBC) network and remotely sensed data from altimeters and synthetic aperture radar (SAR) are used to demonstrate the differences between the models and assess their validity. Each source of observations has its advantages and offers complementary perspectives to assess the models. Buoys offer high fidelity full frequency-direction spectra from which many important wave parameters can be validated; but are limited to their specific locations. Altimeters cover a large expanse of the ocean and have very accurate significant wave heights once corrected (Zieger et al., 2009). The return radar signal from altimeters gives a measure of the mean square slope creating an interesting diagnostic of the high-frequency gravity waves. Complementing the buoys and altimeters, SARs provide a global view of partitioned wave quantities. In practical engineering applications, partitioned wave components are often more intuitive and useful; therefore, we place emphasis on documenting their accuracy using both buoys and SAR observations. Since wave models have the ability to estimate an enormous amount of space-time information, we also inter-compare the models paying close attention to the swell field.

The manuscript will proceed as follows. Section 2 is dedicated to explaining the datasets with separate subsections that describe the model settings, measurements, and forcing fields. Satellite altimeters cover large spatial expanses and we make use of this ability to present a global comparison of the model performance in section 3. To accompaniment the global view, the buoys measurements are used to validate and inter-relate different geophysical wave parameters from the models in section 4. Section 5 follows directly from the outcomes in the previous section to highlight the spatial-temporal differences between the models. A discussion and summary of conclusions are presented in Section 6. 


\section{Datasets}

\subsection{Model Details}

The wave datasets are generated using WW3 version 4.18. WW3 integrates the spectral wave action equation in space and time, with discretized wave numbers and directions. Conservative wave processes like propagation, represented by the local rate of change and spatial and spectral transport terms are balanced by the non-conservative sources and sinks (simply called source terms throughout this manuscript). This study uses a global model grid of $0.5^{\circ}$ resolution in longitude and latitude with a spectral grid composed of 24 directions and 32 frequencies exponentially spaced from 0.037 to $0.7 \mathrm{~Hz}$ at an increment of 10 percent. All model simulations are forced by the same wind fields and sea ice concentrations from CFSR (v2) of Saha et al. (2014), and iceberg distributions (Ardhuin et al. 2011).

Sub-grid features islands than $0.5^{\circ}$ are accounted by apportioning the energy in the zonal and meridional directions (Tolman 2003a,b; Chawla and Tolman, 2008). The nonlinear wave-wave interactions are modeled using the discrete interaction approximation (DIA) of Hasselmann et al., (1985b). Dissipation due to bottom friction uses the SHOWEX formulation to parameterize sandy bottoms, here with a constant sand grain size of $0.2 \mathrm{~mm}$ (Ardhuin et al., 2003). Depthinduced wave breaking is accounted for by using the Battjes and Janssen (1978) formulation with a Miche-style shallow water limiter for maximum energy. The Ultimate Quickest third order propagation scheme is implemented along with garden sprinkler reduction (Tolman, 2002a).

The physical formulations in WW3 that describe the wind input, wave breaking due to whitecapping, and swell dissipation are briefly summarized for each of the four models. Also it must be clarified that data assimilation was not included in any of the model simulations. Our first choice will be referred to as "ST2" and is based on the Tolman and Chalikov (1996) parameterization, as updated by Tolman (2002b). It combines a wind input adjusted to the numerical model of airflow above waves by Chalikov and Belevich (1993), and a dissipation consisting of two separate terms, one for low frequency waves and the other for the highfrequency tail of the spectrum. The high-frequency dissipation shape is adjusted to produce a roll-off of the wave spectrum proportional to $f^{-5}$ at high frequencies, as proposed by Phillips (1958). Next we use the ECMWF WAM parameterization, "ST3", described by Bidlot et al. (2012). This parameterization combines the wind input term originally based on the wave growth theory of Miles (1957) with the feedback on the wind profile parameterized by Janssen (1991). 
119 There is a linear swell dissipation component that was introduced by Janssen (2004). A 120 parametric $f^{-5}$ shape is imposed at frequencies above 2.5 times the mean frequency.

121 Our third choice, "ST4", is described by Ardhuin et al. (2010), and updated by Leckler et al.

122 (2013). This parameterization is built around a saturation-based dissipation, closely following

123 Banner and Morison (2010), a cumulative effect that dissipates short waves due to the breaking

124 of long waves, and a swell dissipation that transitions from non-linear in turbulent conditions, to

125 linear in the viscous regime (Ardhuin et al. 2009, Perignon et al. 2014). The wind input is loosely

126 adapted from the Janssen (1991) formulation, with an important reduction of input at high

127 frequencies necessary to achieve a balance with the whitecapping term. This modification

128 reduced the unrealistic large drag coefficients under high winds but it removed the wave age

129 dependence in the wind stress, which is not realistic (Rascle and Ardhuin 2013). It should be

130 noted that this set of parameterizations does not have any prescribed shape of the high frequency

131 tail, which tends to decrease like $f^{-4.5}$, which is typically not steep enough for frequencies higher

132 than $0.4 \mathrm{~Hz}$. The wind-wave growth parameter $\beta_{\max }$ in Ardhuin et al., (2010) is set to 1.25 for our

133 implementation otherwise we use the same settings as Rascle and Ardhuin (2013).

134 The last set of parameterizations, "ST6", is largely inspired from the energy balance 135 determined from the Lake George measurements of Young et al. (2005). This model uses a 136 nonlinear wind input that relaxes in strong winds and steep waves to represent air flow 137 detachment (Donelan et al., 2006). The whitecapping dissipation accommodates a wave-breaking 138 threshold described by Babanin et al., (2001) and cumulative behavior at small scales (Manasseh 139 et al., 2006, Young and Babanin, 2006). These two characteristics are similar to that of ST4 but 140 are implemented differently. Swell dissipation due to non-breaking effects are included and are 141 based on losses due to turbulence within the ocean (Babanin, 2006, 2011). This non linear swell 142 dissipation term is always active. In the presence of breaking waves, this term is relatively small; 143 however, it can become the dominant energy sink near the peak frequencies of the spectrum 144 when the spectral density drops below the wave-breaking threshold. A separate source term is 145 used to account for the losses resulting from the interaction of waves with opposing winds and is 146 based on laboratory experiments of Donelan (1999). Like ST4, ST6 has no designated shape of 147 the high frequency tail based on a limiter as in ST2 and ST3. 
Both in-situ observations from buoys and remotely sensed measurements from a space borne satellite are used to compare to the modeled results. The NDBC provides quality controlled wave data from their extensive network. Since our purpose is to assess overall errors on the global

152

153

154

155

156

157

158

159

160

161

162

163

164

165

166

167

168

169

170

171

172

173

174

175

176

177 scale, the buoys were chosen to be sufficiently far from the coastlines and located in deep water shown in Fig. 1. All buoys chosen have full frequency-direction spectra available for comparison to the wave model. The 2-dimensional wave spectra are created using the maximum entropy method (MEM) described in Earle et al. (1999) and the high frequency tail was cut-off at $0.4 \mathrm{~Hz}$ to match the highest frequency well resolved by the buoy. The model spectra are interpolated in time and space to match the buoy observations. Portilla et al., (2009) demonstrate that buoy spectra are typically noisy, so they are smoothed in time with a 3 hour running mean and then are interpolated to match the wave model spectral resolution. The averaging in time and spectral space results in a sufficiently smoothed spectra for further analysis.

ENVISAT altimeter data are used to compare with the modeled datasets. Significant wave heights are measured by the active $\mathrm{Ku}$-band radar. The data are quality controlled and calibrated to in-situ buoy measurements by Queffeulou and Croize-Fillon (2010). Only data with strong signal to noise ratio and free from anomalous objects and land are used in the analysis. The normalized radar cross section $\left(\sigma_{0}\right)$ has proven to be a valuable source of information for wave modeling. This is due to the fact that $\sigma_{0}$ is a measure of high frequency wave components and the extensive dataset covers the oceans with long time series. For example, Ardhuin et al., (2010) used $\sigma_{0}$ to estimate the mean square slope ( $m s s$ ) to calibrate the wave breaking coefficients of their parameterization. Following Rascle and Ardhuin (2013) the mss is estimated using

$$
m s s_{A L T}=\frac{0.48}{\exp \left(\left(\sigma_{0}+1.4\right) \times(0.1 \log (10))\right)}
$$

where 1.4 is a bias correction in $\mathrm{dB}$ derived from collocated satellites by Tran et al. (2005), 0.48 is a Fresnel coefficient described by Chapron et al., (2000), and the $0.1 * \log (10)$ factor makes the conversion from a linear scale to $\mathrm{dB}$. Since the model only resolves the prescribed frequency range with the largest frequency of $0.72 \mathrm{~Hz}$ in the given settings, it is necessary to correct the mss. This is achieved by the empirical relation of Vandemark et al., (2004) and is a function of the wind speed at $10 \mathrm{~m}$ elevation (U10):

$$
m s s_{M O D}=\int_{0}^{2 \pi} \int_{0.037}^{0.72} k^{2} E(f, \theta) d f d \theta+0.0035+0.0093 \log (U 10)
$$


178 where $k$ is the wave number and $E(f, \theta)$ is the frequency $(f)$ - direction $(\theta)$ wave spectrum. From 179 Eqn. 2 the $m s s$ is linearly proportional to the fourth moment of the wave spectrum since $k^{2}$ is 180 proportional to $f^{-4}$ in deep water. Therefore the $m s s$ is strongly influenced by the high frequency 181 wave components. Lastly the wind speeds (U10) from the altimeter are used to assess the forcing 182 from CFSR. The wind speed is calculated from a 2-parameter algorithm composed of the 183 significant wave height and the $\sigma_{0}$ described by Gourrion et al., (2002). This geophysical model 184 function has less bias than the widely applied 1-parameter algorithm by Witter and Chelton 185 (1991). However, because of errors in the estimate of the significant wave height, the wind speed 186 calculated with the 1-parameter algorithm by Abdalla (2012) has random errors similar to the 2187 parameter geophysical model function (Zieger et al., 2009).

188 ENVISAT is also equipped with a C-band advanced SAR which is able to achieve high 189 resolution images of the sea surface. Due to the velocity bunching mechanism, wave spectra can 190 be resolved through a non-linear transformation described by Hasselmann et al., (1985a). The 191 level-2 product by the European Space Agency (ESA) uses the quasi-linear approximation of 192 Chapron et al. (2001) to estimate the wave spectra. The motion of small scale waves are not 193 adequately resolved by the SAR and create a blurring effect known as the azimuth cutoff (e.g. 194 Kerbaol et al., 1998). Despite these complications, the quasi-linear approximation accurately 195 estimates swell parameters as demonstrated by Collard et al., (2009). The swell partitions from 196 ENVISAT's SAR are used to extend the spatial coverage provided by moored buoys. In this 197 study we limit ourselves to the best quality SAR data with well imaged swells having wind 198 speeds of 3 to $9 \mathrm{~m} / \mathrm{s}$.

\subsection{Forcing datasets}

200 The wave model uses hourly winds from the Climate Forecast System Reanalysis (CFSR) 201 version 2 of Saha et al., (2010, 2014). The system is composed of a coupled atmosphere, ice, and 202 land surface models. The nominal resolution is $0.3^{\circ}$. CFSR has proven its worthiness in recent 203 wave hindcasts described by Chawla et al., (2013), Rascle and Ardhuin (2013), and Stopa and 204 Cheung, (2014a). Ice concentrations are taken from CFSR, and iceberg concentrations of 205 Tournadre et al. (2008) are used to derive a partial wave blocking according to Ardhuin et al. 206 (2011). 
To demonstrate the errors from the forcing wind field, the CFSR wind speed is compared to derived measurements from ENVISAT's altimeter and presented in Fig. 2. A 7-point running average is used to smooth the altimetry measurements along the satellite tracks. This is approximately equivalent to the $\sim 0.3^{\circ}$ resolution of CFSR. The model data is linearly interpolated in time and space to match the altimeter. Typical error metrics of the normalized bias (NBIAS), root mean square error $(R M S E)$, correlation coefficient $(R)$, and the scatter index $(S I)$ are used to assess the validity of the model estimates, $y$, to the observations $x$ :

$$
N B I A S=\frac{\bar{y}-\bar{x}}{\sqrt{\frac{1}{n} \sum_{i=1}^{n}\left(x_{i}\right)^{2}}}
$$

$$
R M S E=\sqrt{\frac{1}{n} \sum_{i=1}^{n}\left(y_{i}-x_{i}\right)^{2}}
$$

$$
R=\frac{\sum_{i=1}^{n}\left(y_{i}-\bar{y}\right)\left(x_{i}-\bar{x}\right)}{\sqrt{\sum_{i=1}^{n}\left(y_{i}-\bar{y}\right)^{2}} \sqrt{\sum_{i=1}^{N}\left(x_{i}-\bar{x}\right)^{2}}}
$$

$$
S I=\frac{1}{x} \sqrt{\frac{1}{n} \sum_{i=1}^{n}\left[\left(y_{i}-\bar{y}\right)-\left(x_{i}-\bar{x}\right)\right]^{2}}
$$

where the over bar denotes mean and $n$ denotes the number of data points.

The top panel of Fig. 2 shows the dispersion of error for the entire year of 2011. The colorbar co-locations. The normalized bias is slightly negative and is influenced by the weaker wind speeds which have less impact on wave development. The root mean square error is $\sim 1.4 \mathrm{~m} / \mathrm{s}$, the datasets are highly correlated with $R=0.93$, and there is a high precision shown by the scatter index of $\sim 16 \%$. At the wind speeds over $20 \mathrm{~m} / \mathrm{s}$ the CFSR overestimates the observations by 2 $\mathrm{m} / \mathrm{s}$, although the altimeter wind speed algorithm at high wind speeds are expected to have large errors with positive biases (Quilfen et al., 2006; Hanafin et al., 2012; Zieger et al., 2009). The corresponding spatial normalized bias is shown in the bottom panel and binned in $2^{\circ}$ increments.

228 Most of the biases are less than $\pm 5 \%$ and usually underestimate the wind speeds by $2 \%$. A notable negative biased region extends along the Equator and is most likely related to predominantly low wind speeds and uncertainties in the altimeter backscatter, $\sigma_{0}$, estimated at near- 
231 nadir incident angles (Brown 1978; Naderi et al., 1991). The Inter-tropical convergence zone is

232 characterized by low wind speeds, and surface currents (e.g. Quilfen et al., 2001). These

233 conditions can create biases in the altimeter wind speeds, therefore the validity of the CFSR

234 along the Equator is not clear. The results presented here have similar errors as those presented

235 by Stopa and Cheung (2014a), who completed a more comprehensive study of the CFSR winds

236 and their applicability in wave hindcasting. In general, the wind speeds compare well with the

237 observations and are a sufficient dataset to force the wave model.

238

239

240

241

242

243

244

245

246

247

248

249

250

251

252

253

254

255

256

257

258

259

260

\section{Comparison with altimeters}

The advantage of estimating errors with global coverage is that regional inaccuracies can be identified. This distribution of the spatial errors helps identify the physical processes responsible for the discrepancies. Altimetry measurements from ENVISAT are used throughout this analysis. The same procedure as the wind comparison is implemented but a 9-point running mean is used to smooth the altimetry data to match the $0.5^{\circ}$ wave data. We first diagnose the model significant wave height, $H s=4 \sqrt{ } m 0$, where

$m 0=E(f) d f d$.

Fig. 3 shows maps of errors for each of the four model parameterizations. ST2 consistently overestimates the wave heights by $15-25 \%$ or $\sim 0.5 \mathrm{~m}$. These biases are slightly higher $(\sim 20 \mathrm{~cm})$ than the published biases presented in Tolman et al., (2002) or Tolman (2003a) but have the same spatial structure. As noted by Chawla et al., (2013) the model was adjusted to NCEP analyses for the years 2000-2001, and should be re-tuned for recent CFSR winds. The spatial pattern of ST3 is similar to that of ST2 but has reduced biases on the order of $+5 \%$ across the oceans with a few negative regions. This is an improvement compared to the results presented in Arduin et al., (2010) using Bidlot et al., (2007) and shows near homogeneous small positive bias. ST4 and ST6 have similar features with overestimation in the extra-tropics and underestimation in the low-latitudes $\left(25^{\circ} \mathrm{S}-25^{\circ} \mathrm{N}\right)$ consistent with the significant wave height biases presented in Rascle and Ardhuin (2013) and Zieger et al., (2015). In the development of ST6, a constant value for the attenuation coefficient in the parameterization for the swell dissipation contributes to a bias gradient between the high and low latitudes; therefore ST6 implements a steepness dependent attenuation coefficient resulting in a very similar formulation to that of ST4 (Zieger et al., 2015). In general, all models have an underestimation of wave heights near the Equator in the 
261

262

263

264

265

266

267

268

269

270

271

272

273

274

275

276

277

278

279

280

281

282

283

284

285

286

287

288

289

290

291

western Pacific. This bias might be due to insufficient sub-grid blocking and lack of wave reflection from islands (Ardhuin et al., 2010).

The measured mss from ENVISAT provides an opportunity to compare the high frequency wave components with an extensive dataset on the global scale. Since measures of the mss from the satellite (Eqn. 1) and model (Eqn. 2) are indirect, we focus on documenting the precision of the models shown in Fig. 4 through the scatter index. All models have a large scatter near the Equator similar to the regions with the largest Hs biases suggesting these low wave height regions might be related to the high frequency wave components. Some of the mss discrepancies near the Equator can partially be attributed by the wind biases and the inability of the $0.3^{\circ}$ wind forcing to describe small scale wind patterns with sufficient detail. The wave height comparison in Fig. 3 shows ST2 overestimates the wave heights but the mss typically behave reasonably well with typical scatter indices less $17 \%$. ST3 follows ST2 and has the same spatial pattern but with an increase of scatter in the low latitudes $\left(25^{\circ} \mathrm{S}-25^{\circ} \mathrm{N}\right)$. In ST4, the scatter indices are reduced in the low latitudes compared to ST3. The notable difference between these models and ST4 is the reduction of the scatter index in the Southern Ocean with typical values less than 8\%. In ST6, there is more scatter in the low latitudes and mid latitudes $\left(25^{\circ}-50^{\circ} \mathrm{N}\right)$ when compared to ST4 despite similar spatial distributions.

A quantitative approach to resolve the nonlinear behavior of errors as a function of the sea state is to compute the biases for incremental wave heights. In order to mitigate sampling artifacts noted by Tolman (1998), each bin is chosen to have an equal number of data pairs $(n=100)$. This subsample is randomly chosen from a larger population and lies within a range that is double the increment width of $0.5 \mathrm{~m}$. For each sample of points, the normalized bias is given by the median of 20 different random samples. These results are expected to be less influenced by the sampling artifacts since each point is equally weighted with 100 points. The sampling size $(n=100)$ and number of samples $(m=20)$ is varied and the results were found to be insensitive (not shown).

Fig. 5 shows errors of the $H s$ as a function of the sea state. In general the altimeter has a positive bias in estimating wave heights below $1.5 \mathrm{~m}$ and this can be erroneously interpreted as a model underestimation. With ST2, Hs are overestimated for all wave conditions with a reduction in the higher percentiles. For the majority of the wave conditions (10-90\%), ST2 has a positive bias on the order of 10-18\% matching the results depicted in Fig. 2 . ST3 has a consistent $+5 \%$ 
292 error for most sea states with the exception of waves larger than the 99th percentile where the 293 positive bias increases with height. ST4 and ST6 behave similarly with a slight underestimation 294 of the small wave heights $<2.5 \mathrm{~m}$, a trivial positive bias from 2 to $11 \mathrm{~m}$, and then the errors 295 reduce to almost 0 for the largest wave heights. The largest differences between ST4 and ST6 296 occur when the wave heights are less than the 50th percentile where ST6 is seen to underestimate 297 the waves more than ST4. It is important to mention that both ST4 and ST6 match the upper 298 percentiles $>99 \%$ very well, which are often essential for engineering applications. On the whole, 299 each model behaves reasonably well for the larger part of the wave conditions from 1.5-7 m, 300 with biases typically less than $15 \%$.

301

\section{Comparison with buoys}

302

To complement this global view, directional wave buoys are utilized to inspect higher order 303 spectral moments and partitioned quantities. The orbital velocity at the surface $(m 2)$, average 304 wave period (Tm02), average spreading (spr), Stokes drift at the surface (uss), and the (pseudo) 305 mean squared slope ( $m s s)$ are computed from the matching spectra using

$306 m 2=\iint f^{2} E(f, \theta) d f d \theta$

$307 \quad T m 02=\sqrt{\frac{m 0}{m 2}}$

$308 \operatorname{spr}=\sqrt{2\left(1-\sqrt{\frac{\left(\iint \cos (\theta) E(f, \theta) d f d \theta\right)^{2}+\left(\iint \sin (\theta) E(f, \theta) d f d \theta\right)^{2}}{(M 0)^{2}}}\right)}$

309 uss $=\left|\iint 4 \pi f k(\cos (\theta), \sin (\theta)) E(f, \theta) d f d \theta\right|$

$310 m s s=\iint k^{2} E(f, \theta) d f d \theta$

311 where the integrals range across all directions and frequencies from 0.037 to $0.4 \mathrm{~Hz}$ to match the 312 lowest frequency resolved by the model and the highest frequency resolved by the buoy. The 
313 orbital velocity is often a key parameter in sediment transport applications, the design of 314 engineering structures (Wilberg and Sherwood 2008) and has important implications in remote 315 sensing (Kerboal et al., 1998). The average period, Tm02 is more dependent on the high 316 frequency components than the wave period calculated from ratio $m-1$ to $m 0$. The Stokes drift is 317 heavily weighted by the high frequency components and to a lesser extent the longer wave 318 waves. Besides search and rescue applications, this parameter strongly influences ocean mixing 319 through Langmuir circulation (e.g. Li and Garrett 1997) and has applicability in ocean 320 momentum-flux studies (Tamura et al., 2012). The mss is proportional to the fourth moment of 321 the spectrum, and is thus even more influenced by the spectral tail.

322 Error statistics are computed regionally for buoys in the NW Atlantic (Atl), Gulf of Mexico 323 (GoM), Caribbean Sea (Car), NE Pacific (NEP), California (Cal), and Hawaii (Haw) depicted in 324 Fig. 1. In order to graphically represent several wave parameters and error metrics in one plot a 325 Taylor diagram is utilized (Taylor 2001). The normalized standard deviation (NSTD), centered 326 root means square error (CRMSE),

$N S T D=\sqrt{\frac{1}{n} \sum_{i=1}^{n}\left(y_{i}-\bar{y}\right)} / \sqrt{\frac{1}{n} \sum_{i=1}^{n}\left(x_{i}-\bar{x}\right)}$

$328 \quad C R M S E=\sqrt{\left(\frac{1}{n} \sum_{i=1}^{n}\left(y_{i}-\bar{y}\right)-\left(x_{i}-\bar{x}\right)\right)^{2}} / \sqrt{\left(\frac{1}{n} \sum_{i=1}^{n}\left(x_{i}-\bar{x}\right)\right)^{2}}$

329

330

331

332

333

334

335

336

337

338

339

340

341

and correlation coefficient of Eqn. 5 are implemented in Fig. 6. The colors represent the different wave parameters and the symbols correspond to the regions of Fig. 1. It is clear that the lower order moments $H s$ and $m 2$ typically have the best match to the buoys with the highest correlation, lowest CRMSE, and NSTDs are close to 1. The ratio of the two quantities is proportional to TmO2 and typically has larger CRMSE than the $H s$ and $m 2$ since both of these quantities have associated errors. The spr has the largest errors of any parameter with correlations on the order of 0.5 and $C R M S E>0.75$. This suggests that the description of the directional distribution within the model spectra is the largest source of error. In general, the DIA broadens the spectrum in frequency and direction compared to the exact interaction and introduces a source of error (Hasselmann et al., 1985b; Rogers and van Vledder 2013). ST2 typically produces a larger variability than the observations (NSTD>1) and regional biases are seen for the wind-wave dominated regions of the NW Atlantic, Gulf of Mexico, and Caribbean Sea. ST3 is relatively consistent for all wave parameters and no obvious pattern is related to the 
342 parameters or the regions. ST4 is similar to ST3 and matches the observation's variability very 343 well and within $\pm 5 \%$ of the NSTD and have typical CRMSE $<0.5$. In ST6 the errors are less 344 regional and more systematic. The higher order moments uss and mss have too much variability 345 compared to the observations, but the model still correlates well with the observations. In 346 summary, all the models have the largest errors in the directional spread and to a lesser extent the 347 higher order moments.

348 Buoy data shows that the mss increases with wind speed and wave height. Taking advantage 349 of this property, Ardhuin et al., (2010) used the mss derived from altimeters to effectively tune 350 the cumulative dissipation term. Following this approach, the $m s s^{6} \mathrm{~s}$ from all buoys are plotted in 351 terms of wind speed and wave height in Fig. 7. Each point represents the average mss based on 352 incremental binned wind speeds $\left(1 \mathrm{~ms}^{-1}\right)$ and wave heights $(0.5 \mathrm{~m})$. The buoy measurements in 353 the top right panel demonstrate the general relationship: for a given wind speed the mss increases 354 with $H s$ or alternatively for a given $H s$ the $m s s$ increases with wind speed. In ST2 under weak 355 wind conditions $(<5 \mathrm{~m} / \mathrm{s})$ when little wave growth is expected, the $m s s$ is too large suggesting an 356 incorrect balance between the dissipation and wind input. From academic tests of Zieger et al. 357 (2015) it is clear the dissipation term might be too weak from 0.2-0.4 Hz of their Figure 4(b). 358 Even with these errors, the mss gradient in ST2 for a given wind speed is clearly visible 359 qualitatively matching the physical behavior of the buoys. On the other hand in ST3, mss 360 gradient is not as discernible, meaning the dissipation, wind input, and nonlinear wave-wave interaction terms are not accurately balanced for the high frequency wave components. ST4 matches the buoy observations very well suggesting the altimetry measurements that Ardhuin et al., (2010) used to tune the model were a robust sample of the ocean and captured the wave conditions at these buoys. ST6 displays the correct relationship with the wind and wave heights, but the mss is too large, demonstrating an incorrect balance in the high frequency wave components under all wind and wave conditions. In summary, all models except ST4 have difficulty in precisely matching the details of the mss under all wind and wave conditions.

Next we focus our attention on partitioned wave parameters since for many users these 369 quantities can be more intuitive in practical engineering applications. Wave partitioned quantities from the buoy and model are calculated using an adaptation of the Portilla et al., (2009) partitioning scheme. The significant wave height, energy-weighted peak wave period (Tp), peak wave direction $(D p)$, and average direction spread (spr) are computed for each wave partition. 
373 Next matching partitions between the model and buoy are determined by minimizing the spectral 374 distance of the peak period and direction in spectral space. We follow Delpey et al., (2010)'s suggestion and limit the distance to $0.3 \mathrm{~Hz}$-rad to ensure our partitions are within close proximity to one another. The partitions are then classified as wind waves or swell by using the wave age which is defined as the ratio of the peak phase speed $C_{p}$ of the partition to wind speed $U 10$. Wind waves are defined when $C_{p} / U 10<1.2$ and swells when $C_{p} / U 10>1.2$ according Pierson and Moskowitz (1964) and Alves et al., (2003).

To complement the analysis of bulk wave parameters, partitioned wave quantities are plotted on a Taylor diagram in Fig. 8. The partitions are not separated in terms of wind wave and swell conditions, but only minor differences in the overall errors of each component are found (not shown). The random errors of the direction approximately have a CRSME of $\sim 0.25$ with a correlation of 0.95 while the peak periods have a slightly larger range of errors. This is due to the fact that the spectral distance was minimized. In general, all models have partitioned wave heights that are reasonably correlated within the range of 0.7-0.9. Both ST2 and ST3 typically overestimate the variability of the wave heights while ST4 and ST6 closely match the variability of the observations. Lastly, all models are poorly estimate the directional spread of the partitions, characterized by low correlation and large CRMSE. This error was not reduced by improving the resolution of the model from 24 to 36 directions.

Fig. 9 shows the normalized bias for the overall $H s$ and partitioned quantities under both wind wave and swell conditions for all regions. This discrete wave age distinction of 1.2 might induce misclassification especially for broad-banded wind waves when the peak phase speed might not be representative for the entire partition. This limit is tested by making the wave age less than 1.2 for wind waves and larger than 1.2 for swells. The overall effect is minimal (not shown) and in same general pattern still exists, so we use the wave age threshold of 1.2 to classify the different wave regimes. Each model adequately resolves the peak period and direction with typical errors less than $\pm 5 \%$. There does not seem to be any regional biases with these quantities or any errors related to their wind wave or swell classification. The largest errors are in the partitioned wave heights and directional spread. Partitioned data pairs are only considered when the spectral distance is less than $0.3 \mathrm{~Hz}-\mathrm{rad}$. Therefore the wind waves and swell do not correspond to errors in the overall Hs. All models underestimate the directional spread for swells in the Caribbean, NE Pacific, and California. This suggests that the errors have 
common sources. Knowing that the DIA produces too broad spectra, there must be missing processes or errors in other parameterizations. Ardhuin et al., (2012) and Ardhuin and Roland (2012) suggested that the currents and coastal reflections can contribute to these errors. Another common error is the positive bias of swell heights exceeding $10 \%$ in Hawaii.

As previously demonstrated, ST2 overestimates the cumulative significant wave heights. From this analysis it is clear that both the wind waves and swell waves contribute to this bias. Swells typically contribute a larger bias on the order of $5 \%$ more than wind waves. In Hawaii ST2 matches the swell directional spreads reasonably well while they are underestimated for wind waves. For ST3, the swell and wind wave heights follow the same pattern of biases in each region. It is interesting to note that in the Gulf of Mexico, Caribbean, NE Pacific, and California there is a slight negative or negligible bias for the total $H s$ but a positive bias for the partitioned wave heights. ST4 has very small errors $(< \pm 6 \%)$ for significant wave heights computed from the entire spectrum but errors in partitioned wave heights can exceed this amount. In the Atlantic, the wind wave heights have the largest errors but the overall significant wave heights have a small underestimation. In general, ST4 has reduced errors in the direction spread compared to the other models. In ST6, the overall significant wave height is underestimated in all regions and these results agree with the altimeter data presented in Fig. 3. ST6 has smaller swell wave height biases than ST4 but otherwise the errors follow the same pattern. In summary, all models match the direction and period well, but the energy and directional distribution can have considerable errors.

Wave roses in Fig. 10 represent the occurrence of events per direction and magnitude offering a means to further explore the directional errors. Since the swell wave heights are typically over estimated in Hawaii and the buoys are exposed to swells from both hemispheres, this region is used as a representative example. In Hawaii, there are consistent trade winds generating considerable waves (Stopa et al., 2013). In order to exclude these locally generated events and concentrate on swells generated from far-field sources only instances with wave periods larger than $15 \mathrm{~s}$ are retained. All models generally have the same directional distribution with this average climate perspective. They have the same dominant wave component from $310^{\circ}$ which matches the buoys. The models tend to favor the swells from the northwest with a more westerly direction than the observations. Consistent with the previous analysis, ST2 overestimates swell wave heights shown by a larger percentage of the tallest waves $(>3 \mathrm{~m}$ for 
each directional bin). For example when waves are taller than $3.75 \mathrm{~m}$ and from the NW the relative percentages of this directional bin are 34\%,12\%, 9\%, 3\%, and 4\% for ST2, ST3, ST4, ST6 and the buoys respectively. In general the directional distributions are similar for all models with only small differences in the number of events. Similarly the swells from the south are shifted slightly to the south-southwest compared to the observations. The directional distribution can be improved by increasing the directional resolution of the model (not shown). In this implementation the 24 directions adequately resolves the number of events but the directional details of each swell are not sufficiently characterized. The models overestimate the swells from the south which rarely exceed $1.25 \mathrm{~m}$. This helps explain the positive biases in Fig. 9. The South Pacific is littered with islands and atolls which might not be properly accounted for using Chawla and Tolman (2008) sub-grid coefficients. In addition currents not included here, are a likely source of directional errors since Gallet and Young (2014) demonstrate that currents can refract swells up to $\pm 10^{\circ}$.

\section{Space-time model comparison}

The preceding discussion and comparison demonstrates that there can be considerable differences in high spectral moments, partitioned quantities, and directional spread. In order to further explore the model disparities the space-time wave structure is examined. Empirical orthogonal function (EOF) analysis is an efficient technique for analyzing the dominant modes of variability in geophysical datasets (e.g. Hannachi et al., 2007; Stopa and Cheung, 2014b). Here we apply the method to detect spatial-temporal differences between the models by analyzing the ratio of significant wave heights as

$$
s_{i j}^{k l}=\frac{H s_{i j}^{k}}{H s_{i j}^{l}}-\left(\frac{1}{N} \sum_{j=1}^{N} \frac{H s_{i j}^{k}}{H s_{i j}^{l}}\right)
$$

where $N$ is the number of time points, indices $i$ and $j$ denote space and time respectively, and the superscripts $k$ and $l$ denote indices for a source term parameterization: ST2, ST3, ST4, and ST6. The metric, $s_{i j}$, highlights the variation of the residuals between the two models by removal of the mean. For a given model pair, $s_{i j}$ can be written $s_{i j}=\phi_{i m} z_{m j}$ where $\phi_{i m}$ are the eigen vectors or EOFs and $z_{m j}$ is the principle component for mode $m$. The corresponding eigen values, $\lambda_{\mathrm{m}}$ describe a fraction of the total variance as 
$463 \sigma_{m}^{2}=\lambda_{m} / \sum \lambda$

464 and indicates the percentage of variance explained by each mode.

465 This method has the ability to objectively determine the model differences on any time scale. 466 Here we focus time scales on the order of days since it is beneficial to describe the model 467 differences on the same time frame as typical wave forecasts. Therefore we limit the hourly time 468 series to 76 hours. Fig. 11 shows the EOFs for all model pairs using an example time series from 469 January 17-20, 2011. It should be noted that this time series is not unique and the results are 470 representative of the datasets. The $H s$ contours for 5 and $10 \mathrm{~m}$ are given in black to indicate the 471 larger sea states. This figure displays the first principal component and typically captures 30$47240 \%$ of the variation for all model pairs. The second and third components with $\sim 20 \%$ and $\sim 15 \%$ 473 of the variance (not shown) have the same dispersion patterns but with more modulations. These 474 modulations can be interpreted as the instantaneous difference in percentage between each model 475 pair. The wave dispersion patterns of swells are clearly seen amongst the noise for all cases and 476 described by varying positive and negative values that originate in extra-tropical sources and 477 extend across the oceans. The width of these strips relates to the length of the time series and 478 area covered by swell.

479 It is expected that the largest differences would be near the generation areas but these results 480 show that the relative differences extend into the far field demonstrating the sensitivity of the 481 models to accurately describe swells. Swells can have lifetimes greater than one week and 482 transverse entire ocean basins (Munk et al., 1963; Snodgrass et al., 1966). The largest storm 483 located in the North Pacific $\left(170^{\circ} \mathrm{E}, 40^{\circ} \mathrm{N}\right)$ shows the differences extend past the Equator into the 484 eastern Pacific. Near the storm sources the whitecapping and wind generation terms dominate. If 485 486 the differences were related solely to discrepancies near the storms the mean would remove these effects after the waves propagated sufficiently far from the source, however this is not the case. The patterns extend considerably beyond this distance indicating the importance of modifying 488 swells in the far field. These results demonstrate that ST4 is similar to all models with typical differences less than 10\%. ST4 and ST6 have the closest resemblance while ST2 and ST3 have the largest differences in excess of $25 \%$.

It is apparent there are differences in how swells are described from each parameterization 492 and to further highlight these features an example swell is used to compare the models. Wave 493 partitions were generated from WW3 using Hanson and Phillips, (2001) watershed partitioning 
494 algorithm. A large swell occurred towards the end of August in the South Pacific with significant 495 wave heights larger than $11 \mathrm{~m}$ and periods in excess of $22 \mathrm{~s}$. The source is determined to be $496\left(167^{\circ} \mathrm{W}, 56.5^{\circ} \mathrm{S}\right)$ on August 24,20111200 UTC from $H s$ and U10 geospatial maps. The location 497 is verified using the swell tracking method described by Collard et al., (2009).

498 Fig. 12 shows the spatial distribution of the partitioned wave heights sufficiently far from the 499 source (>35 arc-degrees on the Earth's surface $\sim 3900 \mathrm{~km}$ ). Great circle routes are plotted for the 500 azimuths $-30^{\circ}, 0^{\circ}, 30^{\circ}, 60^{\circ}, 90^{\circ}$, and $120^{\circ}$ from the storm center. Co-located SAR wave partitions are plotted along equal distances from the source at 40, 60, and 90 arc-degrees (with 502 \pm 5 arc-degrees). Island obstacles are clearly visible such as: Tuamotus (wave heading of $30^{\circ}$ and $4600 \mathrm{~km}$ from source), Hawaii (wave heading of $10^{\circ}$ and $8500 \mathrm{~km}$ from source), and the Galapagos (wave heading of $80^{\circ}$ and $8000 \mathrm{~km}$ from source). It is clear ST2 has the largest wave 505 heights, ST3 and ST4 have similar magnitudes, and ST6 has the smallest wave heights. From a qualitative point of view each model has a similar energy distribution across the basin and results from similar direction source term distributions and the same treatment of the propagation scheme and alleviation of the garden sprinkler effect.

509 The directional differences are explored by taking transects of the swell event from various distances: 4,400, 6,700, and 10,000 km from the source location. Figure 13 plots the transects versus SAR wave partitions that have been co-located with each model. Due the sparse SAR data, wave headings of $5^{\circ}$ bins and \pm 5 arc degree from the source are grouped and the median of each bin is plotted in Figure 13. The shaded region represents the expected SAR errors determined by the standard deviation of the SAR biases presented by Collard et al., (2009) normalized by the number of values. In the near-field it is clear that ST2 over estimates the swell and can be $1.5 \mathrm{~m}$ larger than observations. All other source terms perform reasonably well except at $90^{\circ}$ from the source where all models overestimate the wave heights. In the mid-field all models perform well with ST2 still showing an overestimation on the order of $1 \mathrm{~m}$ on the stronger half of the wave field (headings $>60^{\circ}$ ). Notice that all parameterizations underestimate 520 the wave heights in the weaker side of the wave field (headings $<0^{\circ}$ ). In addition, the range of wave heights is reduced compared to the near-field. In the far-field ST2 matches the SAR 522 observations the best while the other parameterizations are biased low (0.25-0.5 m). In ST4, the 523 swell dissipation transitions between laminar to turbulent boundary layer based on a Reynolds 524 number defined by the orbital wave velocity. It is possible that a better match could be achieved 
525 by adjusting the critical Reynolds number. In this case the parameterization might have 526 transitioned to a laminar boundary layer too late creating the under estimation in the far field 527 since the turbulent component is 2-30 times larger than the viscous component (Ardhuin et al., 528 2009). If the transects are normalized by their respective maximum, there are only small 529 differences between each model (not shown). The percent differences between the 530 parameterizations are always less $10 \%$ which is comparable to the typical magnitudes shown by 531 the EOF analysis in Fig. 11. Here we illustrate that there are only subtle directional differences

532 between swell fields using the four models with slightly larger differences in the near-field.

533

534

535

536

537

538

539

540

541

542

543

544

545

546

547

548

549

550

551

552

553

554

\section{Discussion and Conclusions}

Through the comparison with altimeter data, buoy measurements, and SAR-derived wave partitions, four set of parameterizations available in the WAVEWATCH III modeling framework are evaluated to reveal their strengths and weaknesses. We particularly estimate error metrics for the significant wave height but also higher moments of the frequency spectrum, which are related to the spectral tail, and partitioned wave quantities.

As the model result strongly depends on the accuracy of the wind forcing, we first verified that winds from the Climate Forecasting System Reanalysis (CFSR, Saha et al. 2010) compares reasonably well to the observations, except near the Equator. The nadir-looking altimeter gives less reliable wind speeds in this region that is characterized by low wind speeds, swells, and currents. This is because the surface slopes reduce the radar cross-section due to swell which, is erroneously interpreted as a higher wind speed (e.g. Vandemark et al. 2002; Gourrion et al., 2002). Also, the surface roughness is more strongly related to the wind relative to the surface current and the equatorial current can induce mean differences up to $1.4 \mathrm{~m} / \mathrm{s}$ between remotelysensed wind speed and anemometer measurements (e.g. Quilfen et al., 2001). Despite these complications, errors in CFSR wind speeds influences the high-frequency wave components, in particular the mean square slope ( $m s s$ ) and even affects the overall $H s$ biases. On the one hand, lower spectral moments like $H s, m 2$ and $\mathrm{TmO2}$ perform convincingly well compared to buoy measurements for all models. On the other hand, larger errors of the higher wave moments between the different model runs are confirmed. Complementing the altimetry analysis, the high frequency components are validated with buoy observations using a pseudo-mss defined from the variance of the vertical acceleration. The highest frequency that is well resolved by all buoys is 
$5550.4 \mathrm{~Hz}$. The variability of spectra between 0.2 and $0.4 \mathrm{~Hz}$ is dominant in the $m s s$, and it is too 556 large with ST2 and too small with ST3 while ST4 and ST6 match the behavior of the 557 observations. It is seen that ST6 typically overestimates the energy in the tail when compared to 558 the buoys. It should be noted that when the model frequencies are above $0.8 \mathrm{~Hz}, \mathrm{ST} 4$ and ST6 559 overestimate the energy in the high frequency components (Zieger et al., 2015). These 560 formulations use their parameterizations to create the balance of the high frequency components 561 while ST2 and ST3 are forced to a prescribed $f^{-5}$ shape based. Although the mss only gives a 562 measure of the tail energy level, there is no consensus on the shape of the wind generation or 563 whitecapping dissipation terms in frequency or direction convoluting the correct balance. There 564 are, however, source terms that are unable to produce the observed variability of the mss (see 565 also Ardhuin et al. 2010).

566 The analysis shows the average directional spread is poorly resolved for all the models 567 suggesting more work is needed to accurately describe the full frequency-direction wave 568 spectrum. Increasing the number of directional bins used in the model, from 24 to 36, does help 569 improve the wave direction in a climatology sense like in Fig. 10 but did not improve the 570 performance of the directional spread (Fig. $6 \& 8$ ). Further work is needed on this topic, and 571 data from open ocean conditions will be needed as coastal buoys can be strongly affected by 572 reflection at the shoreline (Ardhuin et al. 2012). In particular the directional spread has 573 implications to studies of acoustic noise generation through Longuet-Higgins wave-wave 574 interaction mechanism (Longuet-Higgins 1950; Ardhuin and Herbers 2013). The spectral wave 575 components at the buoys and SAR co-locations show the periods and directions match the 576 observations very well, but effectively resolving the magnitude and directional spread is less 577 reliable. An EOF analysis of the short time-scale reveals the relative differences between the 578 models is on the order of $\sim 5-15 \%$ and is expected to be related to the swell field. Swell wave 579 heights vary strongly with the choice of parameterization, even though the spatial structure and 580 directional content is similar.

581 Each model has associated errors and they are discussed below with a general description of 582 their strengths and weaknesses. It is clear ST2 overestimates swell wave heights and this creates 583 an overestimation of the total significant wave height. The swell dissipation in ST2 described in 584 Tolman and Chalikov (1996) scales with friction velocity and thus vanishes when the wind speed 585 goes to zero. This appears to be unrealistic as made evident in the positive biases at low sea 
586

587

588

589

590

591

592

593

594

595

596

597

598

599

600

601

602

603

604

605

606

607

608

609

610

611

612

613

614

615

616

states in Fig. 5 and creates the maximum positive bias in the tropics in Fig. 3. It is also highlighted at the buoys in Fig. 7. The partitioned wave analysis shows the wind wave heights are also overestimated and contribute to the overall $H s$ biases. ST2 and ST3 have the largest disparities mainly due to their different formulations of the wind generation and dissipation due to whitecapping.

ST3 has a better match of the $H s$ values than ST2; however the higher order moments have similar errors. The mss has the largest differences compared to ENVISAT in the Southern Ocean. In high sea states the significant wave heights are overestimated. This is largely due to the definition and role of the mean steepness in that parameterization (Ardhuin et al., 2012). . The whitecapping dissipation is sensitive to swell wave heights and, so that the dissipation decreases as the swell height increases explaining the typical overestimation of wind wave heights in Figure 9. The model overestimates swell heights despite its logarithmic swell dissipation form. The example swell field demonstrates the spatial energy distribution is similar to ST4 which a combination of linear and nonlinear swell dissipation components. In the averaged sense, ST3 is a reasonable predictor of the higher order moments such as the Stokes velocity and the mss and can be used under the majority of wave conditions.

ST4 has the lowest significant wave height biases out of all the models and at the global scale they are typically less than $+5 \%$ or $\sim 30 \mathrm{~cm}$. Overall the mss and higher order wave parameters perform well, which is no surprise since the different parts of the breaking dissipation term was tuned with satellite altimeter data by Ardhuin et al., (2010). In terms of partitioned wave quantities, ST4 has some regional biases with an overestimation of swells and wind waves found in the Atlantic and Hawaii. Otherwise errors are typically less than 10\%. The wave heights of ST4 are most similar to all model parameterizations since the percent differences are less than 10\% (Fig. 11). For all sea states ST4 has minimal Hs biases and the higher order wave parameters perform reasonably well demonstrating its robustness.

The newly developed ST6 performs similarly to ST4 and the most notable differences are in the higher order wave parameters and low wave heights. ST6 has large variability and overestimates the high frequency tail seen by the mss and Stokes velocity comparison with the altimeter and buoys. The mss's are well behaved and match the physics of the buoy data with appropriate scaling in terms of wave heights and wind speeds but the positive bias is still evident. The swell dissipation term is always nonlinear in comparison to ST4 which switches between 
617 nonlinear to linear with a Reynolds number threshold (Perignon et al. 2014). The ST6 functional 618 form results in a stronger dissipation of swells, especially far away from the storms. ST6 619 generally produces more accurate swell heights, and this is the only model with slightly negative 620 biases of that parameter. These biases can accumulate in terms of $H s$ errors and create negative 621 biases larger than $10 \%$ as in the case of California. The example swell clearly demonstrates these 622 features and has a wave energy distribution that rapidly decreases in relation to the other models. 623 In terms of short range errors this model parameterization is most similar to ST4 (Fig. 11). The 624 far-field errors have minimal differences since their swell dissipation parameterizations have the 625 same functional form (Zieger et al. 2015).

626 Matching the directional wave components is a difficult task and the wave models are failing 627 to adequately describe the directional spread. The Taylor plots show the performance of the 628 directional spread is lacking performance compared to the other modeled wave parameters. 629 Some of these errors can be attributed to the approximation of the DIA of quadrupled wave-wave 630 term, but tests with exact non-linear interactions produced too narrow directional distributions. 631 However to fully understand the frequency-direction wave spectrum the directional distributions 632 of the source terms must be understood and there is limited knowledge of these distributions. In 633 particular, there are known biases on directional spread in measurements by some types of buoy 634 (O'Reilly et al. 1996). The introduction of non-isotropic dissipation in ST4 and ST6 reduced the 635 biases on the directional spread, but this is still poorly predicted. Dissipation due to breaking and 636 whitecapping are assumed to be omni-directional; however there is no evidence that this is in 637 fact the case since observing and measuring these quantities in the environment is difficult. 638 Further improvements from the wave modeling community should address the directional errors 639 and it is expected these will enhance the overall health of the model.

\section{Acknowledgements}

641 This research would not have been possible without the dedication of Hendrik Tolman, Henrique 642 Alves, and Arun Chawla who have supported the development of the WAVEWATCH-III code. 643 This work was supported by the "Laboratoire d'Excellence" LabexMER (ANR-10-LABX-19), 644 and the National Partnership Program (NOPP) and encompassing NOAA and the Office of 645 Naval Research (ONR) Grant Number N00014-101-0418USA. The NOPP encouraged the 646 development of new model physics and provided a platform to accomplish effective 
647 collaboration with multiple research groups. We would like to thank the two anonymous

648 reviewers and the guest editor Hendrik Tolman for their comments and suggestions that have 649 improved this paper.

650

651

652

653

654

655

656

657

658

659

660

661

662

663

664

665

666

667

668

669

670

671

672

673

674

675

676

\section{References}

Abdalla, S., 2012: Ku-Band Radar Altimeter Surface Wind Speed Algorithm. Mar. Geodes., 35, 276-298

Alves, J. H. G. M., M. L. Banner, and I. R. Young, 2003: Revisiting the Pierson-Moskowitz asymptotic limits for fully developed wind waves. Journal of Physical Oceanography, 33, 1301-1323.

Ardhuin, F., T. H. C. Herbers, P. F. Jessen, and W. C. O’Reilly, 2003: Swell transformation across the continental shelf, Part II: validation of a spectral energy balance equation. Journal of Physical Oceanography, 33, 1940-1953.

Ardhuin, F., B. Chapron, and F. Collard, 2009: Observation of swell dissipation across oceans. Geophysical Research Letters, 36 (L06607).

Ardhuin, F., E. Rogers, A.V. Babanin, J.-F. Filipot, R. Magne, A. Roland, A. van der Westhuysen, P. Queffeulou, J.-M. Lefevre, L. Aouf, and F. Collard, 2010: Semi-empirical Dissipation Source Functions for Ocean Waves. Part I: Definition, Calibration, and Validation. J. Phys. Oceanogr., 40(9), 1917-1941.

Ardhuin, F., J. Tournadre, P. Queffeulou, F. Girard-Ardhuin, and F. Collard, 2011: Observation and parameterization of small icebergs: Drifting breakwaters in the southern ocean. Ocean Modelling, 39, 405-410.

Ardhuin F., A. Roland, F. Dumas, A-C Bennis, A. Sentchev, P. Forget, J. Wolf, F. Girard, P. Osuna, and M. Benoit, 2012: Numerical Wave Modeling in Conditions with Strong Currents: Dissipation, Refraction, and Relative Wind. Journal of Physical Oceanography, 42, 21012120.

Ardhuin, F., and A. Roland, 2012: Coastal wave reflection, directional spread, and seismoacoustic noise sources, J. Geophys. Res., 117, C00J20, doi:10.1029/2011JC007832.

Ardhuin, F. and T. H. C. Herbers, 2013: Noise generation in the solid Earth, oceans and atmosphere, from nonlinear interacting surface gravity waves in finite depth. J. Fluid Mech., 716, 316-348. 
677 Babanin, A.V., Young, I.R., Banner, M.L., 2001: Breaking probabilities for dominant surface 678 waves on water of finite constant depth. J. Geophys. Res. 106, 11659-11676.

679 Babanin, A. V., 2006: On a wave-induced turbulence and a wave-mixed upper ocean layer. 680 Geohpysical Research Letters, 33 (L20605).

681 Babanin, A.V., 2011. Breaking and Dissipation of Ocean Surface Waves. Cambridge University 682 Press, 480, pp.

683 Battjes, J. A. and J. P. F. M. Janssen, 1978: Energy loss and set-up due to breaking of random 684 waves. Proc. 16th Int. Conf. Coastal Engineering (Hamburg), New York, ASCE, 569-587, 685 pp.

686 Banner, M. L., R. P. Morison, 2010: Refined source terms in wind wave models with explicit 687 wave breaking prediction. Part I: Assessment of existing model performance. Ocean 688 Modelling, 33, 177-189.

689 Bidlot, J.R., 2012: Present status of wave forecasting at ECMWF. Proc. ECMWF Workshop on 690 Ocean Waves, Reading, UK, 25-27 June.

691

Bidlot, J., Janssen, P. and S. Abdalla, 2007: A revised formulation for ocean wave dissipation and its model impact. Tech. Rep. Memorandum 509, ECMWF, Reading, UK.

Brown, G., 1978: Backscattering from a Gaussian-distributed perfectly conducting rough surface. IEEE Trans. Antenn. Propag., 26(3) , 472-482.

Caires, S., Sterl, A., Bidlot, J. R., Graham, N. and V. Swail, 2004: Intercomparison of Different Wind-Wave Reanalyses. J. Clim., 17(10), 1893-1913.

Cavaleri, L., Fox-Kemper, B. \& Hemer, M. 2012: Wind-waves in the coupled climate system. Bull. Am. Meteorol. Soc. 93, 1651-1661.

Chalikov, D. V. and M. Y. Belevich, 1993: One-dimensional theory of the wave boundary layer. Bound. Layer Meteor., 63, 65-96.

Chapron, B., H. Johnsen, and R. Garello (2001), Wave and wind retrieval from SAR images of the ocean, Annals of Telecommunication 56, 682- 699.

Chapron, B., Kerbaol, V., Vandemark, D., and T. Elfouhaily, 2000: Importance of peakedness in sea surface slope measurements. J. Geophys. Res. 105 (C7), 17195-17202.

Chawla, A., Spindler, D. M. and H. L. Tolman, 2013: Validation of a thirty year wave hindcast using the Climate Forecast System Reanalysis winds. Ocean Model., 70, 189-206 
707

708

709

710

711

712

713

714

715

716

717

718

719

720

721

722

723

724

725

726

727

728

729

730

731

732

733

734

735

736

Chawla, A. and H. L. Tolman, 2008. Obstruction grids for spectral wave models Ocean Mod., 22(1-2), 12-25.

Collard, F., F. Ardhuin, and B. Chapron, 2009: Monitoring and analysis of ocean swell fields from space: new methods for routine observations. Journal of Geophysical Research, 114 (C07023) doi: 10.1029/2008JC005215.

Dee, D. P., Uppala, S. M., Simmons, A. J., Berrisford, P., Poli, P., Kobayashi, S., Andrae, U., Balmaseda, M. A., Balsamo, G., Bauer, P., Bechtold, P., Beljaars, A. C. M., van de Berg, L., Bidlot, J., Bormann, N., Delsol, C., Dragani, R., Fuentes, M., Geer, A. J., Haimberger, L., Healy, S. B., Hersbach, H., Hólm, E. V., Isaksen, L., Kållberg, P., Köhler, M., Matricardi, M., McNally, A. P., Monge-Sanz, B. M., Morcrette, J.-J., Park, B.-K., Peubey, C., de Rosnay, P., Tavolato, C., Thépaut, J.-N. and F. Vitart, 2011: The ERA-Interim reanalysis: configuration and performance of the data assimilation system. Quart. J. Roy. Meteor. Soc., 137(656), 553-597.

Delpey, M. T., F. Ardhuin, F. Collard, and B. Chapron, 2010: Space-time structure of long ocean swell fields. Journal of Geohpysical Research, 115 (C12037).

Donelan, M.A., 1999. Wind-induced growth and attenuation of laboratory waves, in: Sajadi, S.G., Thomas, N.H., Hunt, J.C.R. (Eds.), Wind-over-wave couplings: perspectives and prospects. Clarendon Press, pp. 183-194.

Donelan, M.A., Babanin, A.V., Young, I.R., Banner, M.L., 2006. Wave-follower field measurements of the wind-input spectral function. Part II: Parameterization of the wind input. J. Phys. Oceanogr. 36, 1672-1689.

Earle, M. D.; Steele, K. E. \& Wang, D. W. C., 1999: Use of advanced directional wave spectra analysis methods. Ocean Engineering, 1421-1434.

Gallet, B. and W. R. Young, 2014: Refraction of swell by surface currents. Journal of Marine Research, 72, 105-126.

Gelci, R., H. Cazalé, and J. Vassal, 1957: Prévision de la houle. La method des densités spectroangulaires, Bull. Inf. Com. Oceanogr. Etude Cotes, 9, 416-435.

Gourrion, J., Vandemark, D., Bailey, S., Chapron, B., Gommenginger, G. P., Challenor, P. G. and M. A. Srokosz, 2002: A Two-Parameter Wind Speed Algorithm for Ku-Band Altimeters J. Atmos. Ocean. Tech., 19(12), 2030-2048. 
Hanafin, J.A., Quilfen, Y., Ardhuin, F., Sienkiewicz, J., Queffeulou, P., Obrebski, M., Chapron, B., Reul, N., Collard, F., Corman, D., de Azevedo, E.B., Vandemark, D. and E. Stutzmann, 2012: Phenomenal Sea States and Swell from a North Atlantic Storm in February 2011: A Comprehensive Analysis. Bull. Amer. Meteor. Soc., 93, 1825-1832.

Hannachi, A.; Jolliffe, I. and D. Stephenson, 2007: Empirical orthogonal functions and related techniques in atmospheric science: A review. Int. J. Climatol., 27 , 1119-1152.

Hanson J. L. and O. M. Phillips, 2001: Automated analysis of ocean surface directional wave spectra. J. Atmos. Ocean. Techn. 18(2): 177-293.

Hasselmann, K., R. K. Raney, W. J. Plant, W. Alpers, R. A. Shuchman, D. R. Lyzenga, C. L. Rufenach, and M. J. Tucker, 1985a: Theory of synthetic aperture radar ocean imaging: A MARSEN view. Journal of Geophysical Research, 90 (C3), 4659-4686.

Hasselmann, S., Hasselmann, K., Allender, J.H. and T. P. Barnett, 1985b: Computations and parameterizations of the nonlinear energy transfer in a gravity-wave specturm. Part II: Parameterizations of the nonlinear energy transfer for application in wave models. J. Phys. Oceanogr. 15(11), 1378-1391.

Janssen, P.A.E.M., 1991: Quasi-linear theory of wind-wave generation applied to wave forecasting. J. Phys. Oceanogr. 21, 1631-1642.

Janssen, P.A.E.M., 2004: The interaction of ocean waves and wind. Cambridge University Press, Cambridge, pp 312.

Kerbaol V., B. Chapron and P. Vachon, 1998: Analysis of ERS-1/2 synthetic aperture radar wave mode imagettes, J. Geophys. Res. 103(C4), 7833-7846.

Komen G.J., L. Cavaleri, M. Donelan, K. Hasselmann, S. Hasselmann, P.A.E.M Janssen, 1994: Dynamics and Modelling of Ocean Waves. Cambridge University Press, 532 pp.

Leckler, F.; Ardhuin, F.; Filipot, J.-F. and A. Mironov, 2013: Dissipation source terms and whitecap statistics Ocean Model., 2013, 70 (9), 62-74

Li, M., Garrett, C., 1997. Mixed layer deepening due to Langmuir circulation. J. Phys. Oceanogr. 27, 121-132.

Longuet-Higgins, M. S., 1950: A theory of the origin of microseisms. Phil. Trans. R. Soc. A., $243,1-35$. 
Manasseh, R., A.V. Babanin, C. Forbes, K. Rickards, I. Bobevski, A. Ooi, 2006: Passive acoustic determination of wave-breaking events and their severity across the spectrum. Journal of Atmospheric and Oceanic Technology, 23(4), 599-618

Munk, W. M., G. R. Miller, F. E. Snodgrass, and N. F. Barber, 1963: Directional recording of swell from distant storms. Philos. Trans. Roy. Soc. London, A255, 505-584.

Naderi, F. M.; Freilich, M. H. and D. G. Long, 1991: Spaceborne radar measurement of wind velocity over the ocean - an overview of the NSCAT scatterometer system. Proc. IEEE, 79(6), 850-866.

O’Reilly, W. C., T. H. C. Herbers, R. J. Seymour, and R. T. Guza, 1996: A comparison of directional buoy and fixed platform measurements of Pacific swell, J. Atmos. Ocean Technol., 13, 231-238.

Perignon, Y.; Ardhuin, F.; Cathelain, M. and M. Robert, 2014: Swell dissipation by induced atmospheric shear stress J. Geophys. Res., 2014, 119 (10), 6622-6630

Pierson, W. J., and L. Moskowitz, 1964: A proposed spectral form for fully developed wind seas based on the similarity theory of S. A. Kitaigorodskii. Journal of Geophysical Research, 69, 5181-5190.

Phillips, O.M., 1958: The equilibrium range in the spectrum of wind generated waves. Journal of Fluid Mechanics, 4, 426-434

Portilla, J., F. J. Ocampo-Torres and J. Monbaliu, 2009: Spectral partitioning and identification of wind sea and swell. J. Atmos. Oceanic. Technol, 26, 107-122.

Queffeulou, P. and D. Croizé-Fillon, 2010: Global altimeter SWH data set, version 7, May 2010. Tech. rep., Ifremer.

Quilfen Y., C. Bertrand, and D. Vandemark, 2001: The ERS scatterometer wind measurement accuracy: Evidence of seasonal and regional biases. Journal of Atmospheric And Oceanic Technology, 18(10), 1684-1697.

Quilfen, Y., Tournadre, J. and B. Chapron, 2006: Altimeter dual-frequency observations of surface winds, waves, and rain rate in tropical cyclone Isabel. Journal of Geophysical Research, 111, C01004.

Rascle, N. and F. Ardhuin, 2013: A global wave parameter database for geophysical applications. Part 2: Model validation with improved source term parameterization, Ocean Modelling, 70, 174-188. 
Rogers, W. E., A. V. Babanin, and D. W. Wang, 2012: Observation-Consistent Input and Whitecapping Dissipation in a Model for Wind-Generated Surface Waves: Description and Simple Calculations. J. Atmos. Oceanic Technol., 29(9), 1329-1346.

Rogers, W. E. and G. P. van Vledder, 2013: Frequency width in predictions of windsea spectra and the role of the nonlinear solver. Ocean Modelling, 70, 52-61.

Roland, A. and F. Ardhuin, 2014: On the developments of spectral wave models: numerics and parameterizations for the coastal ocean, Ocean Dynamics, 64, 833-846.

Saha, S., Moorthi, S., Pan, H.L., Wu, X., Wang, J., Nadiga, S., Tripp, P., Kistler, R., Woollen, J., Behringer, D., Liu, H., Stokes, D., Grumbine, R., Gayno, G., Wang, J., Hou, Y.T., Chuang, H.Y., Juang, H.M.H., Sela, J., Iredell, M., Treadon, R., Kleist, D., Delst, P.V., Keyser, D., Derber, J., Ek, M., Meng, J., Wei, H., Yang, R., Lord, S., Dool, H.V.D., Kumar, A., Wang, W., Long, C., Chelliah, M., Xue, Y., Huang, B., Schemm, J.K., Ebisuzaki, W., Lin, R., Xie, P., Chen, M., Zhou, S., Higgins, W., Zou, C.Z., Liu, Q., Chen, Y., Han, Y., Cucurull, L., Reynolds, R.W., Rutledge, G., , Goldberg, M., 2010: The NCEP Climate Forecast System Reanalysis. Bull. Amer. Meteor. Soc. 91, 1015-1057.

Saha, S., Moorthi, S., Wu, X., Wang, J., Nadiga, S., Tripp, P., Behringer, D., Hou, Y.-T., Chuang, H.-Y., Iredell, M., Ek, M., Meng, J., Yang, R., Mendez, M. P., van den Dool, H., Zhang, Q., Wang, W., Chen, M. and E. Becker, 2014: The NCEP Climate Forecast System Version 2. J. Clim., 27(6), 2185-2208.

Stopa, J.E., J-F. Filipot, N. Li, K. F. Cheung, Y-L. Chen, L. Vega, 2013: Wave energy resources along the Hawaiian Island chain. Renewable Energy, 55, 305-321.

Stopa, J. E., and K. F. Cheung, 2014a: Intercomparison of wind and wave data from the ECMWF Reanalysis Interim and the NCEP Climate Forecast System Reanalysis, Ocean Modelling, 75, 65-83.

Stopa, J. E., and K. F. Cheung, 2014b: Periodicity and patterns ocean wind and wave climate. Journal of Geophysical Research - Oceans 119(8), 5563-5584.

Snodgrass, F. E., G. W. Groves, K. Hasselmann, G. R. Miller, W. H. Munk, W. H. Powers, 1966: Propagation of ocean swell across the Pacific, Philos. Trans. R. Soc. London, Ser. A, 249, 431-497.

Tamura, H., Miyazawa, Y. and L.-Y. Oey, 2012. The Stokes drift and wave induced-mass flux in the North Pacific. J. Geophys. Res., 117. 
828 Taylor, K. E., 2001: Summarizing multiple aspects of model performance in a single diagram. J. 829 Geophys. Res. Atmos., 106(7), 7183-7192.

830 Tolman, H. L., 1998: Effects of observation errors in linear regression and bin-average analyses. 831 Quart. J. Roy. Meteorol. Soc., 124(547), 897-917.

832 Tolman, H. L., B. Balasubramaniyan, L. D. Burroughs, D. V. Chalikov, Y. Y. Chao, H. S. Chen 833 and V. M. Gerald, 2002: Development and implementation of wind generated ocean surface 834 wave models at NCEP. Weather and Forecasting, 17(2), 311-333.

835 Tolman, H. L., 2002a: Alleviating the Garden Sprinkler Effect in wind wave models Ocean 836 Modelling, 4(3-4), 269-289.

837 Tolman, H. L., 2002b: Validation of WAVEWATCH III version 1.15 for a global domain. Tech. 838 Note 213, Environmental Modeling Center, College Park Maryland, USA, 33 pp.

839 Tolman, H. L., 2003a: Treatment of unresolved islands and ice in wind wave models Ocean 840 Mod., 2003, 5(3), 219-231.

841 Tolman, H. L., 2003b: Erratum to "Treatment of unresolved islands and ice in wind wave 842

Tolman, H.L. and D. Chalikov, 1996: Source Terms in a Third-Generation Wind Wave Model. J. Phys. Oceanogr., 26(11), 2497-2518.

Tolman, H. L., M. L. Banner and J. M. Kaihatu, 2013: The NOPP operational wave model improvement project, Ocean Modelling 70, 2-10.

Tolman, H.L., and the WAVEWATCH III ® Development Group. 2014. User Manual and System Documentation of WAVEWATCH III® version 4.18. Technical Note 316, NOAA/NWS/ NCEP/MMAB, 282 pp. + Appendices.

Tournadre, J., Whitmer, K., and F. Girard-Ardhuin, 2008: Iceberg detection in open water by altimeter waveform analysis. J. Geophys. Res. 113 (7), C08040.

Tracy, B. and D. T. Resio, 1982: Theory and calculations of the nonlinear energy transfer between sea waves in deep water. WES Rep. 11. US Army Corps of Engineers.

Tran N., O.-Z. Zanife, B. Chapron, D. Vandemark, and P. Vincent, 2005: Absolute calibration of Jason-1 and Envisat altimeter Ku-band radar cross sections from cross comparison with TRMM precipitation radar measurements. Journal of Atmospheric and Oceanic Technology, 22, 1389-1402. 
858

859

860

861

862

863

864

865

866

867

868

869

870

871

872

873

874

875

876

877

878

879

880

881

882

883

884

885

886

Vandemark, D., N. Tran, B. Chapron, and P. Gaspar, 2002: Direct estimation of sea state impacts on radar altimeter sea level measurements. Geophysical Research Letters 29(24), doi: 10.1029/2002GL015776.

Vandemark, D., B. Chapron, J. Sun, G. H. Crescenti, and H. C. Graber, 2004: Ocean Wave Slope Observations Using Radar Backscatter and Laser Altimeters, J. Phys. Oceanogr., 34(12), 2825-2842.

WAMDI Group, 1988: The WAM Model - A Third Generation Ocean Wave Prediction Model. J. Phys. Oceanogr., 18(12), 1775-1810.

Wilberg, P. L. and C. R. Sherwood, 2008: Calculating wave-generated bottom orbital velocities from surface-wave parameters. Computers and Geosciences, 34(10): 1243-1262.

Witter, D. L. and D.B. Chelton, 1991: A Geosat Altimeter Wind Speed Algorithm and a Method for Altimeter Wind Speed Algorithm Development. J. Geophys. Res., 96 (5), 8853-8860.

Young, I.R., M.L. Banner, M.A. Donelan, A.V. Babanin, W.K. Melville, F. Veron, and C. McCormick, 2005: An integrated system for the study of wind wave source terms in finite depth water. J. Atmos. Oceanic Tech., 22(7), 814-828

Young, I.R., Babanin, A.V., 2006. Spectral distribution of energy dissipation of wind-generated waves due to dominant wave breaking. J. Phys. Oceanogr. 36, 379-394.

Zieger, S., Babanin, A.V., Rogers, W. E. and I. R. Young, 2015: Observation-based source terms in the third-generation wave model WAVEWATCH. Ocean Modelling, in press, doi:10.1016/j.ocemod.2015.07.014

Zieger, S., Vinoth, J. and Young, I. R., 2009: Joint Calibration of Multi-Platform Altimeter Measurements of Wind Speed and Wave Height Over the Past 20 Years. J. Atmos. Ocean. Tech., 26 (12), 2549-2564

\section{List of Tables}

1) Wave model parameterizations with representative references

\section{List of Figures}

1) Buoy locations and names grouped by region from the NDBC network.

2) Wind speed (U10) comparison from model (CFSR) versus co-located altimeter derived ENVISAT data for 2011. In the top panel the dispersion of model winds is given in a density 
scatter plot on a logarithmic scale with corresponding error statistics for the number of data points $(\mathrm{N})$, normalized bias (NBIAS), root-mean-square error (RMSE), scatter index (SI), and correlation coefficient $(\mathrm{R})$. In the bottom panel the spatial distribution of normalized wind speed bias (in percentage) on a $2^{\circ}$ grid.

3) Normalized wave height bias (in percentage) for ST2, ST3, ST4, and ST6 using co-located wave heights from ENVISAT and the model for 2011 gridded in $2^{\circ}$ bins.

4) Scatter indices (in percentage) for ST2, ST ST3, ST4, and ST6 using co-located mean squared slopes from ENVISAT and the model for 2011 gridded in $2^{\circ}$ bins.

5) Normalized wave height bias (in percentage) for ST2, ST3, ST4, and ST6 plotted in terms of sea state $(H s)$.

6) Taylor diagram - colors represent wave parameters significant wave height (black), orbital wave velocity at the surface (red), mean wave period (orange), average directional spread (green), Stokes surface velocity (blue), and the mean squared slope (purple). The six different symbols denote the regions: Atlantic (circle), Gulf of Mexico (square), Caribbean Sea (triangle), Northeast Pacific (diamond), California coast (star), and Hawaii (x). The different grid axis are the NSTD in solid black circles, the CRMSE in dashed green circles, and the correlation coefficient in blue dash-dot lines.

7) Variation of the surface mean square slope estimated from all buoys from 0.037 to $0.485 \mathrm{~Hz}$. Wind speeds at $10 \mathrm{~m}$ height are estimated from the buoy using a logarithmic wind profile and averaged into $0.5 \mathrm{~m} / \mathrm{s}$ bins while wave heights are averaged into $0.5 \mathrm{~m}$ bins to estimate the average mean square slope.

8) Taylor diagram - colors represent partitioned wave parameters of significant wave height (red), peak period (green), energy weight peak direction (blue), and average directional spread (purple). The six different symbols denote the regions: Atlantic (circle), Gulf of Mexico (square), Caribbean Sea (triangle), Northeast Pacific (diamond), California coast (star), and Hawaii (x). The different grid axis are the NSTD in solid black circles, the CRMSE in dashed green circles, and the correlation coefficient in blue dash-dot lines.

9) Normalized bias (in percentage) of swell and wind wave partitioned quantities in all regions.

10) Wave-rose plots - depicting wave climatology in Hawaii using buoys 51101, 51000, 51100, 51002 , and 51004 with waves that have periods larger than $15 \mathrm{~s}$. 
917 11) Spatial distribution of the first Eigen vector of the empirical orthogonal functions (EOFs) 918 between source terms ST2, ST3, ST4, ST6. EOFs were computed from a time series from 1791920 January 2011. Solid contours indicate large sea states (5 and $10 \mathrm{~m}$ wave height).

920 12) Spatial distribution of the swell wave heights (in meters) from the generation source $\left(167^{\circ} \mathrm{W}\right.$, $\left.92156.5^{\circ} \mathrm{S}\right)$ on August 24, $20111200 \mathrm{UTC}$ for ST2, ST3, ST4, ST6. The dashed black lines 922 represent great circle routes with the same wave heading from the source. The dashed red 923 lines represent equidistant from the source. The stipulated grey points represent co-located 924 ENVISAT SAR wave partitions.

925 13) Storm transects showing the wave height distribution versus the wave angle (heading) at 926 equal distances from the storm source: (top) near-field 4,400 km from the source, (middle) 927 mid-field 6,700 km from the source, and (bottom) far-field 10,000 km. Each point represents 928 the median of co-located wave model-SAR wave partitions in $5^{\circ}$ bins. The grey shading 929 region represents error bars of the EVISAT-SAR observations created by the standard 930 deviation of the associated observational error normalized by the number of observations. 

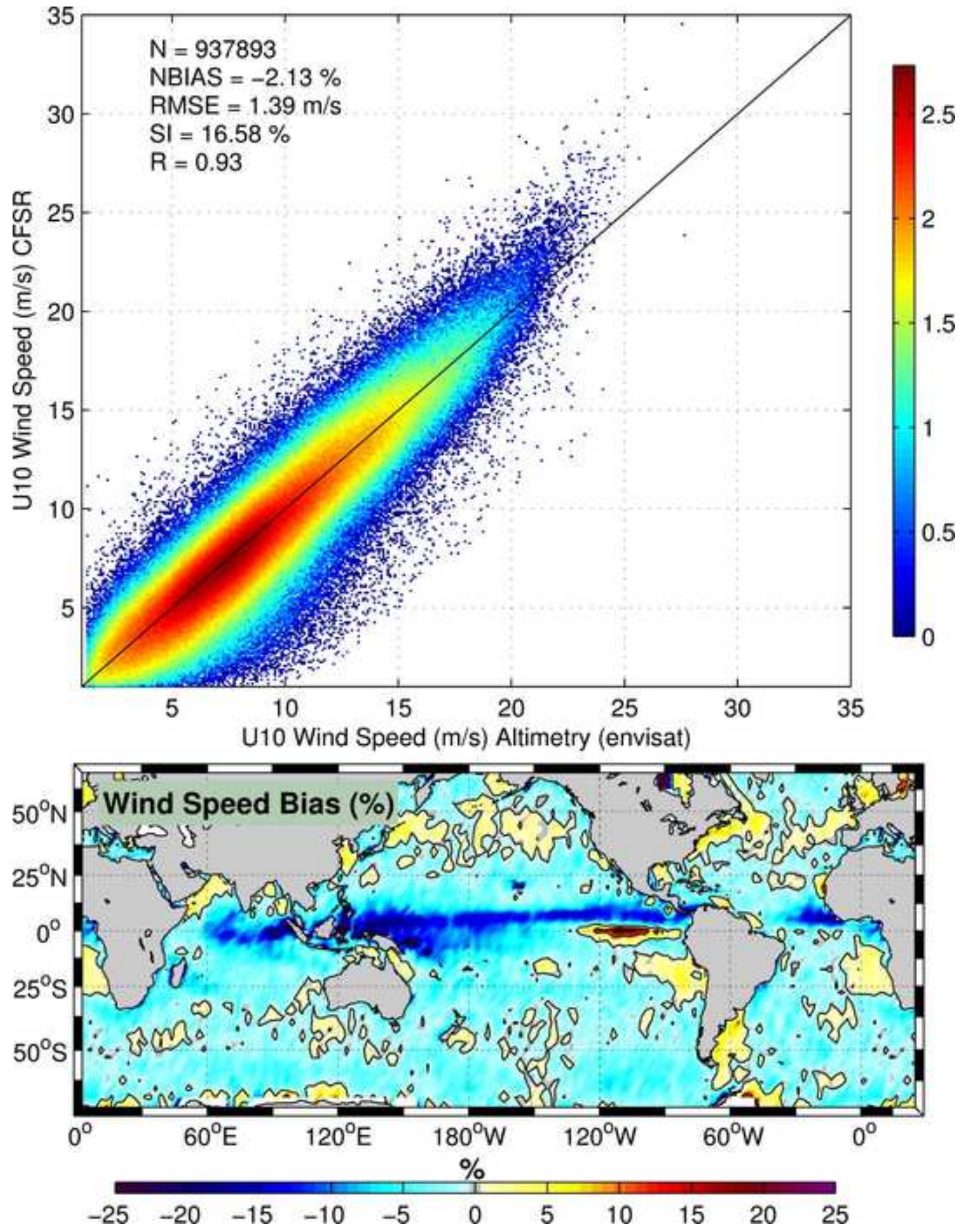

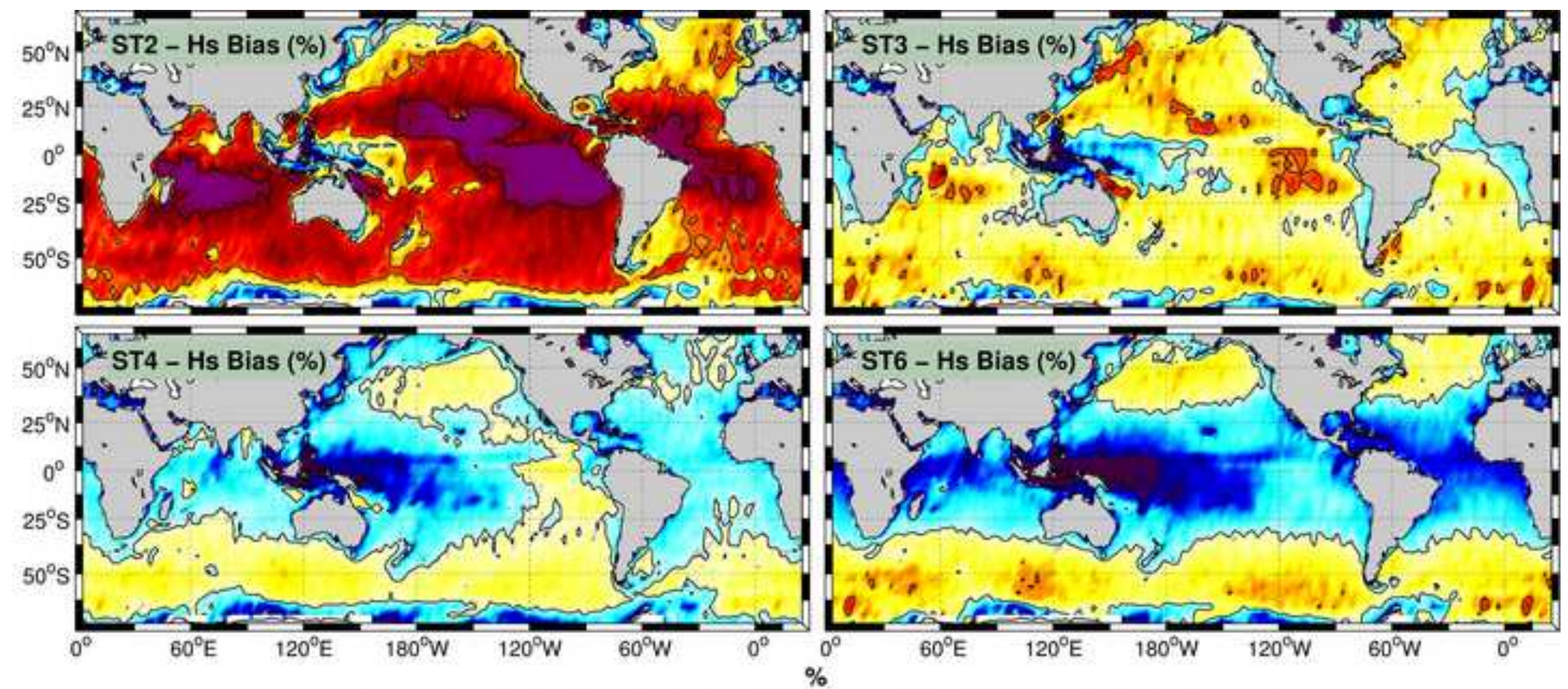

$-25$

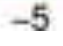

15

20 



5

10

20

25 
Model vs ENVISAT

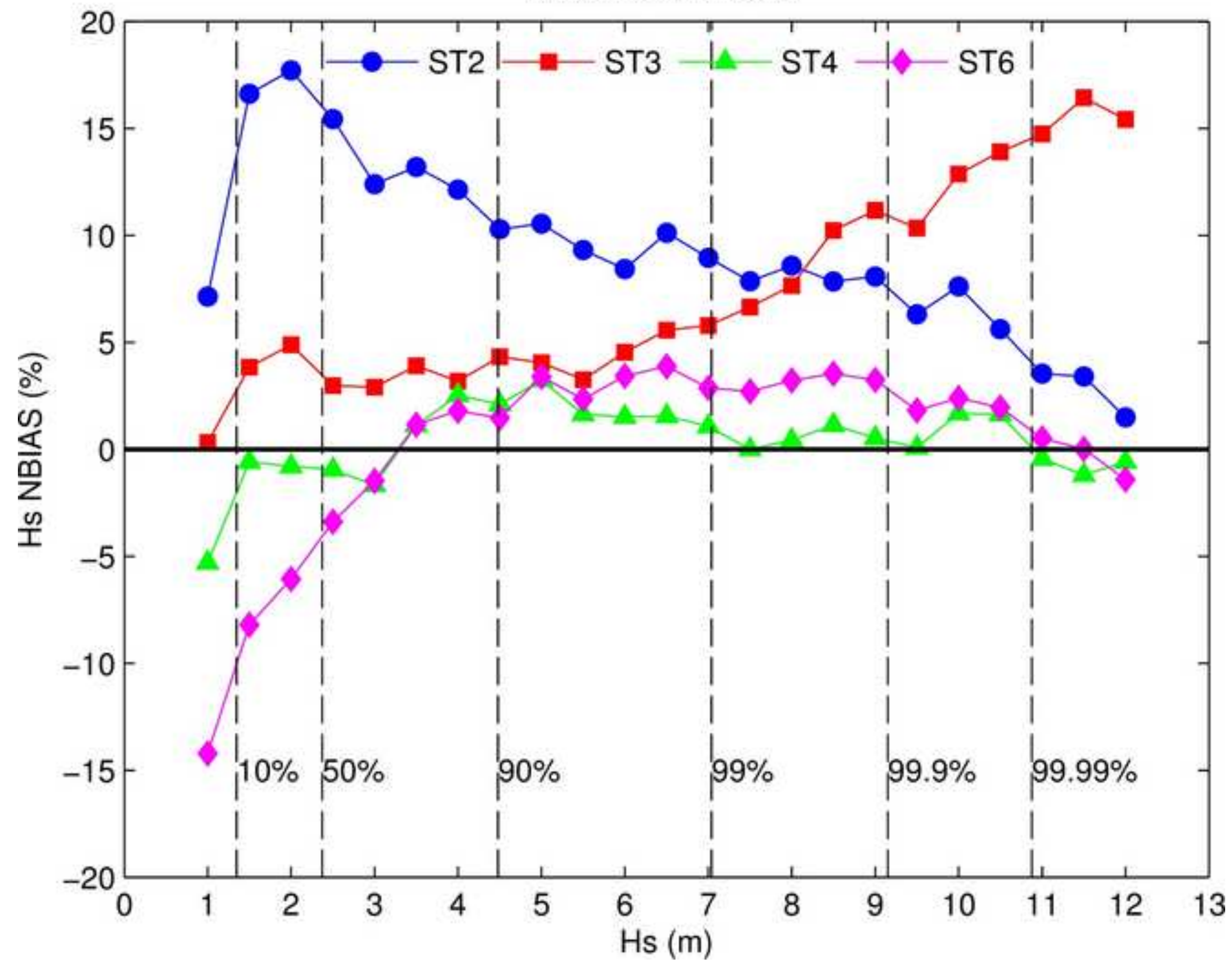



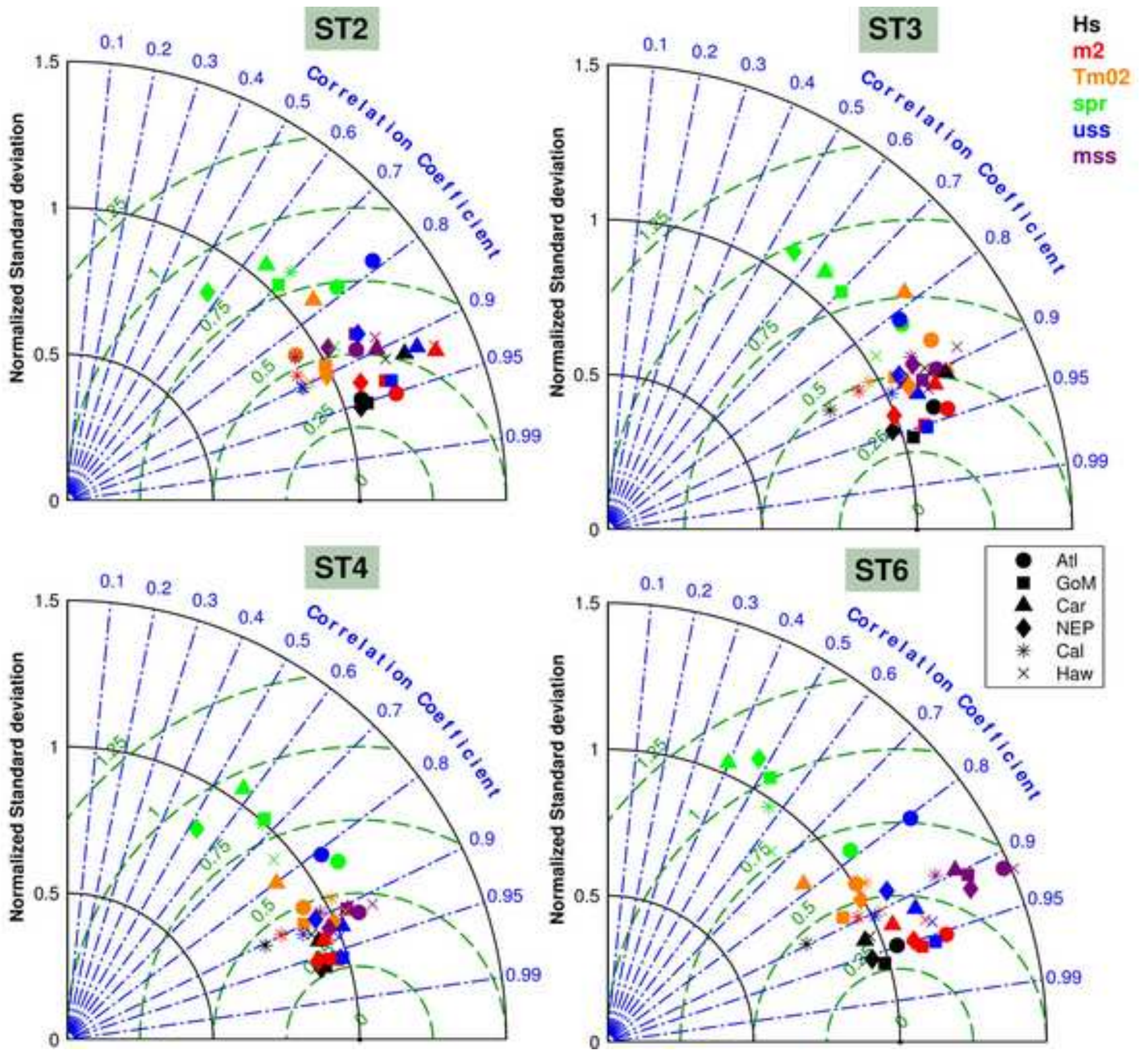

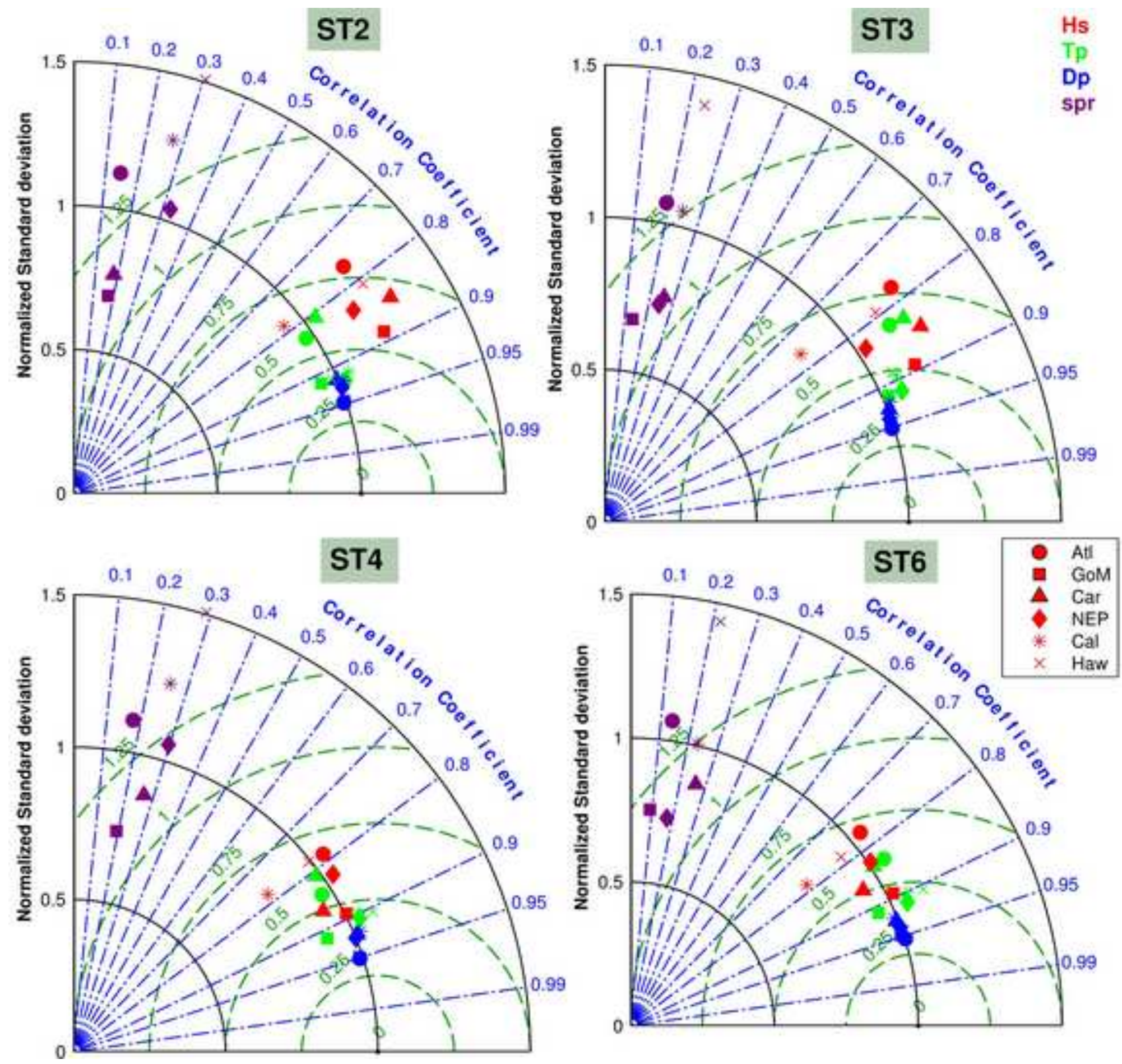



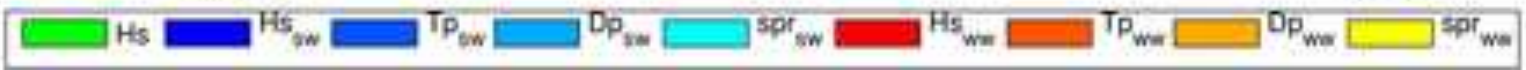





\author{
.
}

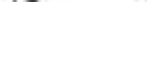




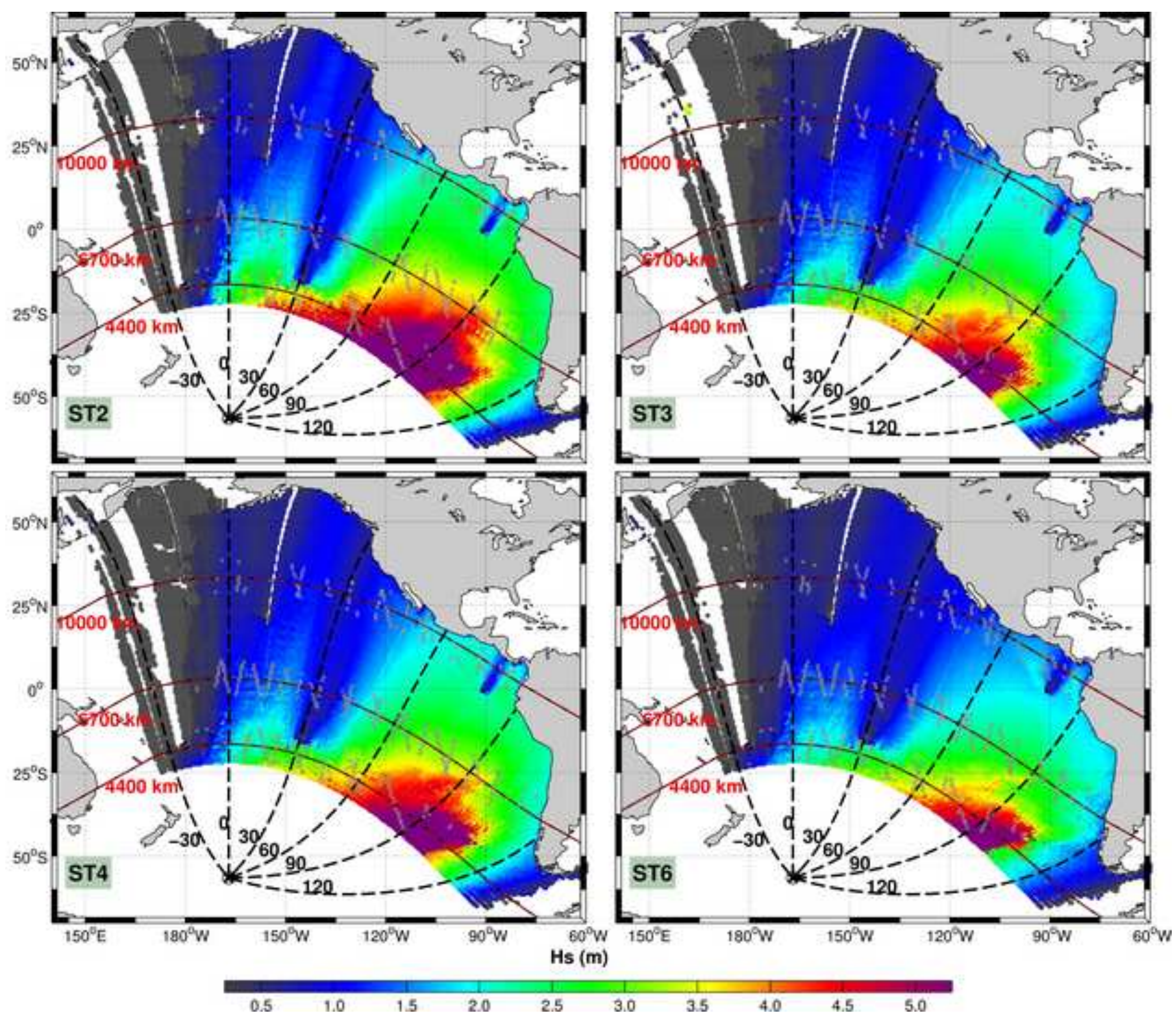


Near-field: Distance from Source $=4400 \mathrm{~km}+1-560 \mathrm{~km}$
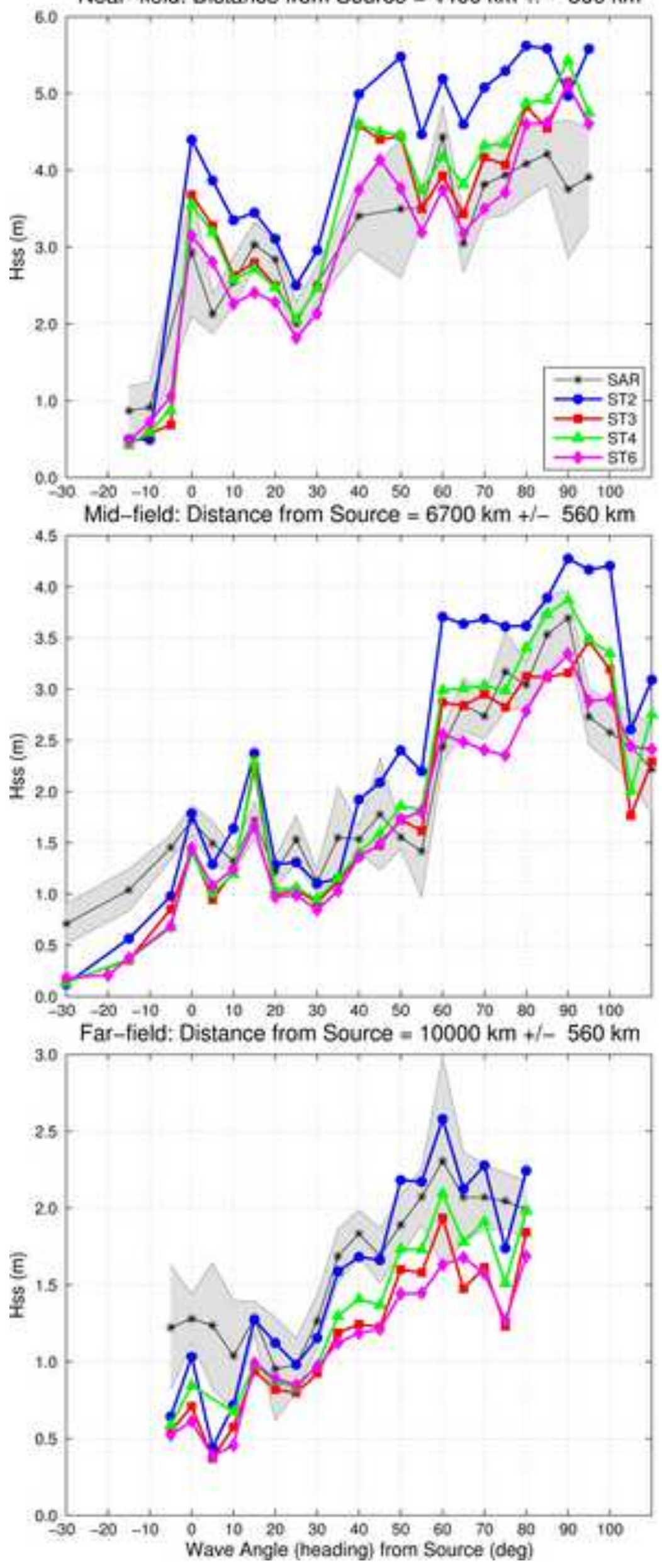


\begin{tabular}{|l|l|}
\hline $\begin{array}{c}\text { Parameterization } \\
\text { Abbreviation }\end{array}$ & \multicolumn{1}{|c|}{ References } \\
\hline ST2 & $\begin{array}{l}\text { Chalikov and Belevich (1993); Tolman and } \\
\text { Chalikov (1996); Tolman et al. (2002) }\end{array}$ \\
\hline ST3 & $\begin{array}{l}\text { Janssen (1991); Janssen (2004); Bidlot et al., } \\
\text { (2007); Bidlot (2012) }\end{array}$ \\
\hline ST4 & $\begin{array}{l}\text { Ardhuin et al., (2010); Arduin et al., (2009); } \\
\text { Leckler et al., (2013); Rascle and Ardhuin } \\
\text { (2013) }\end{array}$ \\
\hline ST6 & $\begin{array}{l}\text { Bababin (2006); Bababin (2011); Rogers et al., } \\
\text { (2012); Zieger et al. (submitted) }\end{array}$ \\
\hline
\end{tabular}

